\title{
Т.В. Новикова
}

\section{КОЛЛИЗИОННЫЙ И МАТЕРИАЛЬНО-ПРАВОВОЙ МЕТОДЫ МЕЖДУНАРОДНОГО ЧАСТНОГО ПРАВА: СООТНОШЕНИЕ И ВЗАИМОДЕЙСТВИЕ}

\begin{abstract}
Статья посвящена анализу вопросов соотношения и взаимодействия коллизионного и материально-правового методов международного частного права. Особое внимание уделяется критике выделения национальных норм «прямого действия» в третий (дополнительный) метод, а равно идеи единства метода международного частного права. Отстаивается тезис о тесном взаимодействии двух методов в регулировании частноправовых отношений с иностранным элементом. Ключевые слова: метод международного частного права, коллизионный метод, материально-правовой метод, унификация.
\end{abstract}

Согласно одному из классических для отечественной науки определений, «метод правового регулирования представляет собой совокупность приемов, способов воздействия права на определенную область общественных отношений» [1. С. 273]. Метод правового регулирования отвечает на вопрос: «Как, каким образом регулируются данные отношения?», - и наряду с предметом правового регулирования выступает основанием разграничения норм права на отдельные отрасли [Там же. С. 272-273].

В международном частном праве традиционно выделяется два метода регулирования: коллизионно-правовой и материально-правовой [2. С. 6372; 3. С. 28]. Опираясь на принципиальную основу их функционирования, Т.Н. Нешатаева именует данные методы как «непрямой - опосредованный, или коллизионный, и прямой, или унифицирующий» [4. С. 15].

Коллизионно-правовой метод заключается в разрешении так называемой коллизионной проблемы, или коллизии (от лат. collisio - столкновение), возникающей в связи с тем, что на регулирование частноправового отношения, осложненного иностранным элементом, могут претендовать несколько правопорядков.

Данный метод является исторически первым для международного частного права, которое начало формироваться в Средние века именно как право коллизионное. Так, И.С. Перетерский и С.Б. Крылов в рамках анализа зарождения доктрины международного частного права приводят широко известную «глоссу Аккурсия», датируемую в составе сборника глосс около 1250 г. и установившую следующий коллизионный тезис касательно пределов действия городских статутов: «Если житель Болоньи прибудет в Модену, он не должен подлежать суду по статутам Модены, которым он не подчинен» [5. С. 17-18]. 
Вместе с тем, поскольку цель коллизионной нормы составляет не регулирование общественного отношения, а лишь указание на применимое к такому отношению право, возникают основания усомниться в правовом характере данной нормы и, соответственно, в корректности обозначения «коллизионно-правовой метод».

Неслучайно ряд авторов избегают употребления характеристики «правовой» при указании на коллизионный метод воздействия. Так, Е.В. Кабатова пишет о коллизионном и материально-правовом методах регулирования [6. С. 21-36], В.В. Гаврилов - о коллизионном и материальноправовом способах регулирования [7. С. 15], В.П. Звеков - о коллизионном и материально-правовом способах правового регулирования [8. С. 10].

Более того, в то время как в отечественной правовой науке получило признание наименование «коллизионное право» [9. С. 25], под которым понимается совокупность коллизионных норм, выступающих в терминологии А.А. Рождественского как нормы «не юридические, а технические» [10. С. 24], зарубежные специалисты проявляют бо́льшую осторожность в этом вопросе. Так, в юриспруденции Великобритании [11. P. 1; 12. Vol. 1. P. 1] и США [13. Р. 1-4] широко используется наименование conflict of laws, которое традиционно переводится на русский язык как «коллизионное право», но дословно может быть переведено исключительно как «конфликт законов», или «коллизия правопорядков». Аналогичным образом, без указания на правовой характер обозначаемой совокупности правил, переводится и используемое французскими учеными словосочетание conflits de lois - «конфликт (столкновение) законов» [14. Р. 171-186; 15. P. 7].

На этом основании можно заключить, что в действительности использование характеристики «правовой» по отношению к коллизионному методу может носить лишь условный характер, в связи с чем представляется предпочтительным оперировать словосочетанием «коллизионный метод регулирования».

Однако придание анализируемому методу некоего «технического» статуса ни в коей мере не умаляет его значения, поскольку от выбора применимого права, которому надлежит регулировать общественные отношения по существу, будет коренным образом зависеть исход соответствующего правового спора. По этой причине мы не можем согласиться с авторами, по мнению которых квалификация коллизионных норм как «ссылочных», направленных «на выработку особого конфликтного приема регулирования», свидетельствует об их недооценке [16. С. 95-101], и не разделяем вытекающие из этого мнения попытки искусственно сочленить коллизионную норму с избранной на ее основе нормой иностранного или отечественного права для формирования некого «регулирующего» единства [6. С. 11].

Важным свойством коллизионных норм (и соответствующего им метода регулирования) является то, что они исторически, а во многом и в настоящее время, являются составной частью права страны суда, т.е. конкретный судья при рассмотрении частноправового спора международного характера обращается в большинстве случаев к коллизионным нормам 
своего национального права. Например, в Российской Федерации значительная часть таких норм содержится в разделе VI ГК РФ [17]. Указанное обстоятельство, сопряженное с тем, что право различных государств зачастую включает различные по содержанию (и правому результату) коллизионные нормы, составляет наиболее существенный недостаток коллизионного метода регулирования.

Попыткой преодолеть обозначенный недостаток выступила унификация - разработка единообразных коллизионных норм и их закрепление в форме международного договора. Примерами в данной области могут выступать международные договоры, разработанные Гаагской конференцией по международному частному праву, в том числе Гаагская конвенция о праве, применимом к международной купле-продаже товаров [18], и Женевская конвенция, имеющая целью разрешение некоторых коллизий законов о переводных и простых векселях [19]. Наиболее впечатляющим примером является Кодекс Бустаманте, принятый в 1926 г. на VI Международной конференции американских государств, который состоит из четырех книг, охватывающих 437 статей, определяющих коллизионное регулирование в самых разных сферах, и действует в настоящий момент для 15 государств Латинской Америки [20. С. 58-59].

Бесспорно, такая унификация позволяет избежать различий в коллизионном регулировании и манипуляций удобным судом с целью получить отсылку к наиболее выгодному правопорядку за счет применения коллизионных норм страны суда. Вместе с тем унификация коллизионных норм не снимает существенного объема сложностей, связанных с механизмом их применения и возникающих, в частности, за счет действия общих коллизионных институтов (нормы непосредственного применения, оговорка о публичном порядке и др.), а также вытекающих из необходимости определять содержание норм применимого права в тех случаях, когда такое право оказывается иностранным по отношению к суду.

Второй метод международного частного права - материально-правовой в отечественной юридической науке также распадается на два вида: международный (унифицирующий) и национальный (составляющий так называемое «право иностранцев»). При этом унифицирующий метод получает набольшее признание среди правоведов [9. С. 15-22], поскольку его цель составляет преодоление коллизии правопорядков за счет действия единообразных международно-правовых норм, специально ориентированных на регулирование частноправовых отношений с иностранным элементом. Как отмечает В.П. Звеков, востребованность данного метода регулирования обусловливается «не только потребностью устранить различия во внутреннем праве государств... но и тем обстоятельством, что внутреннее право нередко оказывается «неприспособленным» для регулирования столь своеобразных отношений» [21. С. 289].

Правовым основанием применения материально-правового (унифицирующего) метода в международном частном праве Российской Федерации выступает п. 3 ст. 1186 ГК РФ, который устанавливает: «Если междуна- 
родный договор Российской Федерации содержит материально-правовые нормы, подлежащие применению к соответствующему отношению, определение на основе коллизионных норм права, применимого к вопросам, полностью урегулированным такими материально-правовыми нормами, исключается».

Наиболее успешным примером унификации материально-правовых норм является Венская конвенция о договорах международной куплипродажи товаров [22], работа по разработке которой была начата под эгидой Международного института унификации частного права в 1929 г. (в первую очередь в рамках разработки Гаагских конвенций 1964 г. [23, 24]) и завершена уже под эгидой Комиссии ООН по праву международной торговли в 1980 г. [25. С. 28-29]. В настоящий момент конвенция насчитывает 89 государств-участников [26] и является одним из важнейших регуляторов частноправовых отношений международного характера.

Что же касается материально-правового метода, проявляющегося в применении норм национального права, непосредственно регулирующих определенные правоотношения с иностранным элементом (например, определяющих правовое положение иностранных лиц на территории государства пребывания - так называемое «право иностранцев»), то этот вопрос является одним из наиболее дискуссионных, и его решение в существенной мере зависит от решения вопроса о природе и содержании международного частного права в целом, а именно от признания указанных норм национального права составной частью международного частного права.

В рамках настоящего исследования отметим, что специфика таких «норм прямого действия» в сравнении как с коллизионными нормами, так и с унифицированными международно-правовыми нормами, послужила основанием для отдельных ученых к выделению третьего - особого - метода международного частного права [27. С. 9].

В этой связи следует указать, что в действительности нормы международного договора, даже выступая в силу ч. 4 ст. 15 Конституции РФ в качестве составной части правовой системы Российской Федерации [28], сохраняют свою генетическую принадлежность системе международного права. Ярким подтверждением изложенного выступает то, что толкование норм международного договора отечественным правоприменителем осуществляется по правилам Венской конвенции о праве международных договоров [29], о чем особо говорится в п. 10 Постановления Пленума Верховного Суда РФ «О применении судами общей юрисдикции общепризнанных принципов и норм международного права и международных договоров Российской Федерации» [30]. Напротив, национальные нормы прямого действия реализуются в ходе ординарного правоприменительного процесса, причем в этом случае речь не идет ни о постановке, ни даже о преодолении коллизионной проблемы. По сути, такие нормы действуют в сферах, в которых возможность применения иностранного правопорядка исключается, во многом в связи с тем, что такие отношения лежат в плоскости публичного права, например по вопросам ввоза и вывоза культурных 
ценностей, порядка трудоустройства иностранных граждан в Российской Федерации и др.

Тем не менее мы полагаем, что при положительном решении вопроса о включении национальных норм прямого действия в состав международного частного права механизм осуществляемого ими регулятивного воздействия будет все же основываться на непосредственном, исключающем постановку коллизионной проблемы, регулировании и поэтому не позволит выделить его в самостоятельный - по отношению к материальноправовому - метод международного частного права.

Завершая анализ методов международного частного права, считаем необходимым остановиться на имеющейся в отечественной правовой науке дискуссии о единстве метода международного частного права. Фундатором концепции единства метода международного частного права считается В.П. Звеков, который указал на взаимодействие «материально-правового и коллизионного способов регулирования, обеспечивающих преодоление коллизионной проблемы» [21. С. 289]. В настоящее время весьма категорично по данному вопросу высказывается Г.К. Дмитриева, по мнению которой методом международного частного права является «совокупность конкретных приемов, способов и средств юридического воздействия, направленного на преодоление коллизии права разных государств» [9. С. 15], в то время как охватываемые методом сnособы регулирования включают коллизионно-правовой и материально-правовой [Там же].

Развернутая критика данной концепции представлена в докторской диссертации Л.П. Ануфриевой [31. С. 100-131] ${ }^{1}$ и включает указание на ряд принципиальных вопросов, ответы на которые приверженцами единства метода международного частного права не даются и в целом вряд ли могут быть даны, в том числе на вопрос о том, «в чем состоит регулятивное воздействие “преодоления"» [Там же. С. 110] и многие другие. Помимо прочего, исследователь указывает на то, что современная наука международного частного права, напротив, свидетельствует о многочисленных попытках выделения дополнительных методов регулирования, что свидетельствует «о явном отсутствии у специалистов опасений по поводу их количества и кажущегося несоответствия этого выкладками общей теории права» [Там же. С. 112].

Признавая обоснованной критику концепции единства метода международного частного права, заключим, что искусственное конструирование единого «метода» с соответствующим переименованием в «способы» принципиально различных коллизионного и материально-правового механизмов воздействия не представляется обоснованным и может быть объяснено исключительно догматическими причинами обеспечения внешней корреляции единого метода и соответствующей ему области права.

\footnotetext{
${ }^{1}$ Критические замечания Л.П. Ануфриевой в адрес концепции единства метода международного частного права, высказанные в более ранней монографии [32] были также воспроизведены в научной статье А.В. Зепалова [33. С. 37-39].
} 
Вместе с тем следует заметить, что даже первоначальные, высказанные В.П. Звековым идеи о преодолении коллизионной проблемы, рассматриваемые как основание идеи о едином методе международного частного права $^{1}$, были отнюдь не столь категоричными. Так, ученый заявляет: «Своеобразие материально-правового и коллизионного способов регулирования достаточно велико, чтобы можно было в каком-либо отношении пренебречь им» [21. С. 289].

Более того, высказывая идеи о преодолении коллизионной проблемы, В.П. Звеков в той же научной статье признает, что включение в состав международного частного права национальных материально-правовых норм есть «одно из традиционных положений советской доктрины в этой области» [Там же. С. 288], в то время как при последовательном проведении в жизнь концепции единого метода, «направленного на преодоление коллизии права разных государств» [9. С. 15], национальные нормы прямого действия неминуемо остаются за рамками международного частного права.

Не подлежит сомнению тот факт, что своеобразие коллизионного и материально-правового способов не означает их тесного взаимодействия при регулировании частноправовых отношений международного характера, однако механизм такого взаимодействия требует уточнения. Так, Л.П. Ануфриева, указывая на взаимосвязь двух методов, раскрывает ее только в рамках коллизионного метода через сочетание «коллизионной и той материальной нормы, к которой она отсылает» [31. С. 119]. Очевидно, что в описанном случае речь идет исключительно о реализации коллизионного метода, и потому он не может иллюстрировать взаимодействие двух методов международного частного права.

Вместе с тем в современных условиях взаимодействие двух методов получает все большее распространение. При этом увеличение числа унифицированных международно-правовых норм (и расширение действия материально-правового метода) не вытесняет национальные коллизионные нормы и тем самым не заменяет коллизионный метод, а, напротив, прямо предусматривает субсидиарное использование коллизионного метода, увеличивая поле их взаимодействия в регулировании частноправовых отношений с иностранным элементом.

Полагаем, что наглядной иллюстрацией может выступить следующий пример: российское юридическое лицо продает товар по договору куплипродажи французской компании, при этом соглашение о применимом праве между сторонами отсутствует. В случае разрешения российским государственным судом возникшего из данного договора спора им будут применены положения Венской конвенции о договорах международной куплипродажи товаров - реализован материально-правовой метод регулирования. Однако по вопросам, которые в упомянутой конвенции не разрешены и

\footnotetext{
1 Заслуживает особого внимания тот факт, что, как указывает Л.П. Ануфриева, в более поздних работах с участием В.П. Звекова «“тональность” отстаивания позиции явно “приглушена"» [31. С. 109].
} 
не могут быть разрешены на основании ее общих принципов, суд должен будет обратиться к национальному праву, избираемому в соответствии с российским коллизионным правом (п. 2 ст. 7 Конвенции), реализуя тем самым коллизионный метод. В силу п. 2 ст. 1211 ГК РФ суд применит отечественное право как право страны-продавца по договору купли-продажи. Таким образом, в рамках одного дела, вытекающего из одного договорного правоотношения международного характера, будут взаимодействовать материально-правовой и коллизионный методы регулирования.

Примечательно, что правовой исход будет совершенно другим в случае, если то же российское юридическое лицо продаст товар туркменской компании, при этом договор купли-продажи, не имеющий положений о применимом праве, будет заключен в Туркменистане. В случае разрешения российским государственным судом возникшего из данного договора спора правовые основания для применения Венской конвенции о договорах международной купли-продажи товаров будут отсутствовать. Более того, применимое национальное право будет определено не на основании коллизионных норм ГК РФ, а в соответствии с коллизионной нормой, унифицированной региональным международным договором - Соглашением стран СНГ о порядке разрешения споров, связанных с осуществлением хозяйственной деятельности [34]. В силу п. «е» ст. 11 указанного соглашения российский суд должен будет применять право Туркменистана как право страны места совершения сделки. Следовательно, в данном случае из-за отличной национальной принадлежности контрагента, сопряженной с местом заключения договора, будет реализован исключительно коллизионный метод регулирования, причем на его международном (унифицированном) уровне.

Подводя итог изложенному, отметим, что наличие в арсенале международного частного права двух особых методов регулирования (коллизионного и материально-правового) обусловлено как онтологическими факторами его формирования, так и существенной спецификой регулируемых им отношений. В этой связи представляется уместным привести высказывание Т.Н. Нешатаевой, сделанное в ходе обоснования полисистемной природы международного частного права: «В результате правоотношение может сложиться только на основе комплекса норм, объединенных самим этим общественным отношением. В этот комплекс войдут коллизионная норма и материальная норма. При этом и та и другая может находиться как в национальном праве, так и в международном договоре» [4. С. 26].

\section{Лuтература}

1. Основы теории государства и права : учеб. пособие / под ред. С.С. Алексеева. М. : Юрид. лит., 1969. 384 с.

2. Ануфриева Л.П. Международное частное право : учебник : в 3 т. М. : БЕК, 2002. T. 1: Общая часть. 288 с.

3. Ерпылева Н.Ю. Международное частное право : учебник : в 3 т. М. : Юрайт, 2015. T. $1.384 \mathrm{c}$.

4. Нешатаева Т.Н. Международное частное право и международный гражданский процесс : учеб. курс : в 3 ч. М. : Городец, 2004. 624 с. 
5. Перетерский И.С., Крылов С.Б. Международное частное право : учебник. М. : Юрид. изд-во НКЮ СССР, 1940. 208 с.

6. Международное частное право : учебник : в 2 т. / под ред. С.Н. Лебедева, Е.Н. Кабатовой. М. : Статут, 2011. Т. 1: Общая часть. 400 с.

7. Гаврилов В.В. Международное частное право : краткий учеб. курс. М. : Норма, 2000. 304 c.

8. Международное частное право : учебник / под ред. Н.И. Марышевой. М. : Волтерс Клувер, 2011.928 с.

9. Международное частное право : учебник / под ред. Г.К. Дмитриевой. М. : Проспект, 2016. $680 \mathrm{c}$.

10. Рождественский А.А. Два этюда. М. : Печатня А. Снегиревой, 1916. 32 с.

11. Briggs A. Conflict of Laws, $3^{\text {nd }}$ ed. Oxford : Oxford University Press - Clarendon Law Series, 2013. 448 p.

12. Dicey, Morris \& Collins on the Conflict of Laws / L. Collins, J. Harris, eds. $15^{\text {th }}$ ed. London : Sweet \& Maxwell, 2012. 2385 p.

13. Hay P., Borchers P.J., Symeonides S.C., Whytock Ch.A. Conflict of Laws. $6^{\text {th }}$ ed. Saint Paul : West Academic Publishing - Hornbook Series, 2018. 1800 p.

14. Holleaux D., Foyer J., Geouffre de La Pradelle G. de. Droit International Privé. Paris : Masson, 1987. $667 \mathrm{p}$.

15. Majoros F. Le Droit International Privé. 3me éd. Paris : Presses Universitaires de France, 1990. $127 \mathrm{p}$.

16. Левитин А. Б. К вопросу о предмете международного частного права // Правоведение. 1959. № 3. С. 95-101.

17. Гражданский кодекс Российской Федерации (часть третья) от 26 ноября 2001 г. № 146-Ф3 // Собрание законодательства РФ. 2001. № 49. Ст. 4552.

18. Конвенция о праве, применимом к международной купле-продаже товаров от 15.06.1955 (Гаага) // Регистр текстов международных конвенций и других документов, касающихся международной торговли. Нью-Йорк, 1971. Т. 1.

19. Конвенция, имеющая целью разрешение некоторых коллизий законов о переводных и простых векселях от 07.06.1930 (Женева) // Собрание законов. 1937. Отд. II, № 18. Ст. 109.

20. Юридическая техника : учеб. пособие / под ред. Н.А. Власенко. М. : Юстиция, $2016.318 \mathrm{c}$.

21. Звеков В. П. К вопросу о соотношении материально-правового и коллизионного способов регулирования в международном частном праве // Советский ежегодник международного права 1973. М. : Наука, 1975. С. 284-292.

22. Конвенция ООН о договорах международной купли-продажи товаров от 11.04.1980 (Вена) // Вестник ВАС РФ. 1994. № 1.

23. Конвенция о Единообразном законе о заключении договоров о международной купле-продаже товаров от 01.06.1964 (Гаага) // Регистр текстов международных конвенций и других документов, касающихся права международной торговли. Нью-Йорк : Организация Объединенных Наций, 1971. Т. І. С. 75-84.

24. Конвенция о Единообразном законе о международной купле-продаже товаров от 01.07.1964 (Гаага) // Регистр текстов международных конвенций и других документов, касающихся права международной торговли. Нью-Йорк : Организация Объединенных Наций, 1971. Т. I. С. 46-74.

25. Матвеева Т. В. Роль международного договора в международном частном праве : дис. ... канд. юрид. наук. М., 2006. 181 с.

26. Конвенция Организации Объединенных Наций о договорах международной купли-продажи товаров // Комиссия ООН по праву международной торговли (ЮНСИТРАЛ) : статус текстов. URL: http://www.uncitral.org/uncitral/ru/uncitral_texts/ sale_goods/1980CISG_status.html (дата обращения: 20.07.2018). 
27. Лунц Л.А., Марышева Н.И., Садиков О.Н. Международное частное право. М. : Юрид. лит., 1984. 336 с.

28. Конституция Российской Федерации : (принята всенар. голосованием 12.12.1993) // Собрание законодательства РФ. 2014. № 31. Ст. 4398.

29. Конвенция о праве международных договоров от 23.05.1969 (Вена) // Ведомости Верховного Совета СССР. 1986. № 37. Ст. 772.

30. О применении судами общей юрисдикции общепризнанных принципов и норм международного права и международных договоров Российской Федерации : Постановление Пленума Верховного Суда РФ от 10.10.2003 № 5 // Бюллетень ВС РФ. 2003. № 12 .

31. Ануфриева Л.П. Соотношение международного публичного и международного частного права (сравнительное исследование правовых категорий) : дис. ... д-ра юрид. наук. М., 2004. 581 c.

32. Ануфриева Л.П. Соотношение международного публичного и международного частного права : правовые категории. М. : Спарк, 2002. 415 с.

33. Зепалов А.В. «Проблема метода» международного частного права // Международное публичное и частное право. 2005. № 3. С. 37-39.

34. Соглашение стран СНГ о порядке разрешения споров, связанных с осуществлением хозяйственной деятельности, от 20.03.1992 (Киев) // Ведомости СНД и ВС РФ. 1992. № 44. Ст. 2472.

Novikova Tatyana V., North Caucasus branch of the Federal state budgetary educational institution of higher education «Russian State University of justice» (Krasnodar, Russian Federation)

CONFLICT AND IS MATERIAL-LEGAL METHODS OF PRIVATE INTERNATIONAL LAW: INTERRELATION AND INTERACTION

Keywords: method of private international law, conflict of laws method, material-legal method, unification.

\section{DOI: $10.17223 / 22253513 / 32 / 13$}

International private law traditionally distinguishes two methods of regulation: collective and substantive. The conflict-of-laws method is to solve the conflict problem arising from the fact that the regulation of private law relations with a foreign element can be claimed by several legal orders.

The substantive method is divided into two types: international (unifying) and national (covering national rules of "direct effect"). The greatest recognition a unifying method because its goal is the overcoming of a conflict of propo-rows due to the action of uniform international legal norms, specifically focused on the regulation of private law relations with a foreign element.

As for the material-legal method, manifested in the application of the rules of national law, directly regulating legal relations with a foreign element, the number of such rules served as the basis for individual scientists (La Lunts, N. I. Marysheva, O. N. Sadikov) to the allocation of the third method of private international law. We believe that in case of a positive decision on the inclusion of such rules in the composition of international private law, the mechanism of their regulatory impact will be based on direct, excluding the formulation of a conflict of laws problem, regulation and therefore will not allow to distinguish it in an independent method.

Particular attention should be paid to the concept of the unity of the method of private international law put forward in the domestic legal science, the founder of which is V.P. Zvekov. Detailed criticism of this concept is presented in the doctoral thesis of L.P. Anomie-ing. Recognizing the justified criticism of the concept of the unity of the method of private international law, we conclude that the artificial construction of a single "method" with the corresponding naming in the "methods" of fundamentally different conflict-of-law and substantive 
mechanisms of influence, does not seem justified. It can be explained by the dogmatic reasons for the external correlation of the unified method and the corresponding area of law.

In modern conditions, the interaction of the two methods is becoming increasingly common. Moreover, the increase in the number of unified international legal norms (and the expansion of the action of the substantive method) does not displace national conflict of laws rules (and does not change the conflict method), but rather directly provides for the subsidiary use of the conflict of laws method, increasing the field of their regulatory interaction. Thus, the presence in the Arsenal of private international law of two special methods of regulation (conflict of laws and substantive law) is due to both the ontological factors of its formation and the essential specifics of the relations regulated by it.

\section{References}

1. Alekseev, S.S. (ed.) (1969) Osnovy teorii gosudarstva i prava [Fundamentals of the Theory of State and Law]. Moscow: Yurid. lit.

2. Anufrieva, L.P. (2002) Mezhdunarodnoe chastnoe pravo [Private International Law]. Vol. 1. Moscow: BEK.

3. Erpyleva. N.Yu. (2015) Mezhdunarodnoe chastnoe pravo [Private International Law]. Vol. 1. Moscow: Yurayt.

4. Neshataeva, T.N. (2004) Mezhdunarodnoe chastnoe pravo i mezhdunarodnyy grazhdanskiy protsess [Private International Law and the International Civil Process]. Moscow: Gorodets.

5. Pereterskiy, I.S. \& Krylov, S.B. (1940) Mezhdunarodnoe chastnoe pravo [Private International Law]. Moscow: Yurid. izd-vo NKYu SSSR.

6. Lebedev, S.N. \& Kabatova, E.N. (2011) Mezhdunarodnoe chastnoe pravo [Private International Law]. Vol. 1. Moscow: Statut.

7. Gavrilov, V.V. (2000) Mezhdunarodnoe chastnoe pravo [Private International Law]. Moscow: Norma.

8. Marysheva, N.I. (2011) Mezhdunarodnoe chastnoe pravo [Private International Law]. Moscow: Volters Kluver.

9. Dmitrieva, G.K. (2016) Mezhdunarodnoe chastnoe pravo [Private International Law]. Moscow: Prospekt.

10. Rozhdestvenskiy, A.A. (1916) Dva etyuda [Two etudes]. Moscow: Pechatnya A. Snegirevoy.

11. Briggs, A. (2013) Conflict of Laws. 3nd ed. Oxford: Oxford University Press - Clarendon Law Series.

12. Collins, L. \& Harris, J. (eds) (2012) Dicey, Morris \& Collins on the Conflict of Laws. 15th ed. London: Sweet \& Maxwell.

13. Hay, P., Borchers, P.J., Symeonides, S.C. \& Whytock, Ch. A. (2018) Conflict of Laws. 6th ed. Saint Paul: West Academic Publishing - Hornbook Series.

14. Holleaux, D., Foyer, J. \& Pradelle, G.de la (1987) Droit International Privé. Paris: Masson.

15. Majoros, F. (1990) Le Droit International Privé. 3rd ed. Paris: Presses Universitaires de France.

16. Levitin, A.B. (1959) K voprosu o predmete mezhdunarodnogo chastnogo prava [On the subject of private international law]. Pravovedenie. 3. pp. 95-101.

17. Russian Federation. (2001) Grazhdanskiy kodeks Rossiyskoy Federatsii (chast' tret'ya) ot 26 noyabrya 2001 g. № 146-FZ [Civil Code of the Russian Federation (Part Three) of November 26, 2001 No. 146-FZ]. Sobranie zakonodatel'stva RF - Legislative Bulletin of the Russian Federation. 49. Art. 4552.

18. UNO. (1971a) Registr tekstov mezhdunarodnykh konventsiy i drugikh dokumentov, kasayushchikhsya mezhdunarodnoy torgovli [Register of texts of international conventions and other documents relating to international trade]. Vol. 1. New York: UNO.

19. League of Nations. (1937) Konventsiya, imeyushchaya tsel'yu razreshenie nekotorykh kolliziy zakonov o perevodnykh i prostykh vekselyakh ot 07.06.1930 (Zheneva) [The Conven- 
tion aimed at resolving some conflicts of laws on transfer and promissory notes from June 7, 1930 (Geneva)]. In: Sobranie zakonov. 1937 [Collected Laws. 1973]. Part II, № 18. Art. 109.

20. Vlasenko, N.A. (ed.) (2016) Yuridicheskaya tekhnika [Legal Writing]. Moscow: Yustitsiya.

21. Zvekov, V.P. (1975) K voprosu o sootnoshenii material'no-pravovogo i kollizionnogo sposobov regulirovaniya $\mathrm{v}$ mezhdunarodnom chastnom prave [On the relationship between substantive and conflict of laws methods of regulation in international private law]. Sovetskiy ezhegodnik mezhdunarodnogo prava 1973 [Soviet Yearbook of International Law 1973]. Moscow: Nauka. pp. 284-292.

22. UNO. (1994) Konventsiya OON o dogovorakh mezhdunarodnoy kupli-prodazhi tovarov ot 11.04.1980 (Vena) [UN Convention on Contracts for the International Sale of Goods dated April 11, 1980 (Vienna)]. Vestnik VAS RF. 1.

23. UNO. (1971b) Registr tekstov mezhdunarodnykh konventsiy $i$ drugikh dokumentov, kasayushchikhsya prava mezhdunarodnoy torgovli [Register of texts of international conventions and other documents relating to international trade law]. Vol. 1. New York: UNO. pp. 75-84.

24. UNO. (1971c) Registr tekstov mezhdunarodnykh konventsiy i drugikh dokumentov, kasayushchikhsya prava mezhdunarodnoy torgovli [Register of texts of international conventions and other documents relating to international trade law].Vol. 1. New York: UNO. pp. 46-74.

25. Matveeva, T.V. (2006) Rol' mezhdunarodnogo dogovora v mezhdunarodnom chastnom prave [The Role of an International Treaty in Private International Law]. Law Cand. Diss. Moscow.

26. UNO. (n.d.) Komissiya OON po pravu mezhdunarodnoy torgovli (YuNSITRAL): status tekstov [UN Commission on International Trade Law (UNCITRAL): the status of texts]. [Online] Available from: http://www.uncitral.org/uncitral/ru/uncitral_texts/sale_goods/1980CISG_ status.html (Accessed: 20th July 2018).

27. Lunts, L.A., Marysheva, N.I. \& Sadikov, O.N. (1984) Mezhdunarodnoe chastnoe pravo [International Private Law]. Moscow: Yurid. lit.

28. Russian Federation. (2014) Konstitutsiya Rossiyskoy Federatsii : (prinyata vsenar. golosovaniem 12.12.1993) [Constitution of the Russian Federation: (adopted by the national vote on December 12, 1993)]. Sobranie zakonodatel'stva RF - Legislative Bulletin of the Russian Federation. 31. Art. 4398.

29. USSR. (1986) Konventsiya o prave mezhdunarodnykh dogovorov ot 23.05.1969 (Vena) [Convention on the Law of International Treaties of May 23, 1969 (Vienna)]. Vedomosti Verkhovnogo Soveta SSSR. 37. Art. 772.

30. Russian Federation. (2003) O primenenii sudami obshchey yurisdiktsii obshchepriznannykh printsipov i norm mezhdunarodnogo prava i mezhdunarodnykh dogovorov Rossiyskoy Federatsii : Postanovlenie Plenuma Verkhovnogo Suda RF ot 10.10.2003 № 5 [On application by courts of general jurisdiction of generally recognized principles and norms of international law and international treaties of the Russian Federation: Regulation of the Plenum of the Supreme Court of the Russian Federation No. 5 of October 10, 2003]. Byulleten' VS RF. 12.

31. Anufrieva, L.P. (2004) Sootnoshenie mezhdunarodnogo publichnogo i mezhdunarodnogo chastnogo prava (sravnitel'noe issledovanie pravovykh kategoriy) [The ratio of public international and private international law (a comparative study of legal categories)]. Law Dr. Diss. Moscow.

32. Anufrieva, L.P. (2002) Sootnoshenie mezhdunarodnogo publichnogo i mezhdunarodnogo chastnogo prava: pravovye kategorii [The ratio of public international and private international law: legal categories]. Moscow: Spark.

33. Zepalov, A.V. (2005) "Problema metoda" mezhdunarodnogo chastnogo prava ["The Problem of Method" of Private International Law]. Mezhdunarodnoe publichnoe i chastnoe pravo - Public International and Private International Law. 3. pp. 37-39.

34. CIS. (1992) Soglashenie stran SNG o poryadke razresheniya sporov, svyazannykh s osushchestvleniem khozyaystvennoy deyatel'nosti, ot 20.03.1992 (Kiev) [The Agreement of the CIS countries on the Procedure for Resolving Disputes Related to the Implementation of Economic Activity, dated March 20, 1992 (Kiev)]. Vedomosti SND i VS RF. 44. Art. 2472. 